\title{
Multimídia impacto digital: ações de extensão em comunidades pacifi- cadas na cidade do Rio de Janeiro
}

\author{
Multimedia digital impact: Extension actions in pacified communities in the city of Rio de \\ Janeiro
}

Autores

Wania Clemente de Castro. Professora Adjunta do IFHT/Uerj

E mail: wania.clemente@terra.com.br

Tatiane Gomes Machado. Pedagoga e Bolsista Proatec IFHT/UERJ

Email: tatianegomes.pm@gmail.com

Michele Silva de Avelar. Coordenadora Pedagógica do Centro de Tecnologia Educacional - CTE/UERJ

E mail: michele.avelar@hotmail.com

Recebido em: 20/07/2016 Aprovado em: 07/04/2017

DOI: $10.12957 /$ interag. 2017.24740

\section{Artigo}

Acreditando no potencial das Tecnologias Digitais de Informação e Comunicação (TDICs) na educação, o Projeto Multimídia Impacto Digital (MID) teve como objetivo a disseminação de pesquisas e de produção de mídias, bem como de ações relacionadas ao desenvolvimento social, econômico, político e cultural de comunidades pacificadas pela polícia do estado do Rio de Janeiro. Buscou ainda estimular a criação de produções de mídia, visando à formação de crianças e adolescentes, residentes nas comunidades do Tuiuti e Mangueira, e à expansão de seus horizontes no âmbito das tecnologias digitais, objetivando compreender como novas mídias podem ser utilizadas em ambiente informal de aprendizagem. O presente trabalho tem por objetivo apresentar os resultados das pesquisas e ações extencionistas realizadas nas comunidades participantes do projeto.

\section{Abstract}

Believing in the potential of Digital Technologies of Information and Communication (TDICs) in education, the project Multimedia Digital Impact (MID) was aimed at disseminating research and production of media, as well as actions related to social, economic, political and cultural growth of communities pacified by the police of the state of Rio de Janeiro. The projects ought to encourage the creation of media productions, for the training of children and adolescents, residents in the communities of Tuiuti and Mangueira, and expanding its horizons within the digital technologies, aiming to understand how new media can be used in an informal setting of learning. This study aims to present the results of research and extension workers actions taken in participating in the project communities. 
Palavras-chave: Mídias digitais; educação e tecnologia; unidade de polícia pacificadora.
Keywords: Digital media, education and technology, pacifying police unit.

Área temática: Educação

Linha de extensão: Mídias e Tecnologia da

Informação.

\section{Introdução}

As transformações na sociedade aliadas ao desenvolvimento das Tecnologias Digitais de Informação e Comunicação (TDICs) têm sido constantes nos dias atuais. Essas tecnologias estão cada vez mais presentes em nosso cotidiano, sendo utilizadas em larga escala em lugares diferenciados, como casas, empresas, comércios e em outros espaços sociais. Elas são meios facilitadores de comunicação, interação social e "impõem mudanças radicais nas formas de acesso à informação, à cultura e ao entretenimento".

As TDICs exercem um papel cada vez mais importante na forma de nos comunicarmos, aprendermos e vivermos. Nesse contexto, novas tendências, tecnologias e culturas surgem fazendo com que haja mudanças nas relações interpessoais e profissionais, como ressalta Kenski:

A evolução tecnológica não se restringe apenas aos novos usos de determinados equipamentos e produtos. Ela altera comportamentos. A ampliação e a banalização do uso de determinada tecnologia impõem-se à cultura existente e transformam não apenas o comportamento individual, mas o de todo grupo social. ${ }^{1}$

É inegável a importância de acompanharmos a evolução tecnológica e a sua influência na complexa sociedade globalizada. Contudo, as diferenças socioeconômicas e educacionais entre a população do Rio de Janeiro ainda são expressivas. Ações voltadas para a educação e a inclusão digital se fazem essenciais para que as tecnologias não contribuam para aprofundar ainda mais as diferenças econômicas e sociais entre os cidadãos, como coloca Postman:

As vantagens e desvantagens de novas tecnologias nunca são distribuídas equitativamen-

te entre a população. Isto significa que toda nova tecnologia beneficia uns e prejudica outros. $^{2}$

Nesse sentido, acredita-se que promover mecanismos para a inclusão digital dos membros de uma comunidade permite que o uso das novas tecnologias aconteça de maneira que venha efetivamente a contribuir para o benefício coletivo.

Cabe destacar que incluir digitalmente não é apenas ensinar os aspectos técnicos da utilização dos dispositivos tecnológicos, mas sim, promover iniciativas que propiciem uma efetiva apropriação, como coloca Nelson Pretto:

[...] inclusão de cidadãos, não como meros consumidores, seja de produtos ou de informações, mas como sujeitos plenos que participam do mundo contemporâneo enquanto 
seres éticos, autônomos e com poder de decisão. ${ }^{3}$

Questões culturais e educacionais devem estar presentes quando falamos em inclusão digital. De acordo com Castells:

Um excluído digital tem três grandes formas de ser excluído. Primeiro, não tem acesso à rede de computadores. Segundo, tem acesso ao sistema de comunicação, mas com uma capacidade técnica muito baixa. Terceiro, (para mim é a mais importante forma de ser excluído e da que menos se fala) é estar conectado à rede e não saber qual o acesso usar, qual a informação buscar, como combinar uma informação com outra e como a utilizar para a vida. Esta é a mais grave porque amplia, aprofunda a exclusão mais séria de toda a História; é a exclusão da educação e da cultura porque o mundo digital se incrementa extraordinariamente. ${ }^{4}$

Nesse contexto, fica clara a necessidade de ir além da perspectiva técnica e do mero acesso. É importante pensar na inclusão digital sob a perspectiva da produção de conteúdos, de autoria e coautoria dos sujeitos no mundo digital, dimensão que efetivamente poderia ser significativa educacional e culturalmente para as comunidades.

É preciso entender as tecnologias digitais de informação e comunicação (TDICs) não apenas como suportes tecnológicos. Deve-se levar em consideração a existência de linguagens, percepções e capacidades que envolvem o uso dessas tecnologias e que devem ser trabalhadas em ações de inclusão digital. Ir além da perspectiva técnica e de acesso significa realizar uma educação para as mídias, cujos "objetivos visam à formação do usuário ativo, crítico e criativo de todas as tecnologias de comunicação e informação".

As tecnologias fazem parte da cultura contemporânea, desempenhando papéis cada vez mais importantes na sociedade. Nesse cenário, sua apropriação crítica e criativa torna-se imprescindível para o exercício da cidadania. Para contribuir para construção de uma sociedade menos desigual e mais justa, é necessário investir em ações que permitam aos cidadãos a construção de uma relação significativa com as mídias:

[...]permitir aos membros de uma comunidade participarem, de modo criativo e crítico, ao nível da produção, da distribuição e da apresentação, de uma utilização das mídias tecnológicas e tradicionais, destinadas a desenvolver, libertar e também a democratizar a comunicação. ${ }^{5}$

Foi nesse contexto, encarando as mídias digitais como impulsionadoras de avanços sociais, que o Projeto "Multimídia Impacto Digital (MID)" surgiu com a proposta de promover ações educacionais e de inclusão digital em comunidades pacificadas pela polícia do estado do Rio de Janeiro, muitas vezes negligenciadas no que diz respeito a serviços públicos e oportunidades de educação e cultura para sua população. Dessa forma, buscou-se contribuir para a inclusão social dos moradores dessas comunidades através do uso das múltiplas mídias digitais como instrumento de construção e exercício da cidadania.

\section{As comunidades e as UPPs}

O programa de Unidades de Polícia Pacificadora (UPPs) surgiu com o objetivo de instituir o policiamento comunitário do Estado Democrático de Direito nas comunidades antes dominadas por criminosos, a fim de desarticular e retomar a presença estatal 
nessas comunidades, inibindo o tráfico de armas e de drogas.

O que alguns questionam nesse processo é o fator social, pois as condições de marginalidade que geram a elevação dos índices de criminalidade precisam ser modificadas. Nesse sentido, argumenta-se sobre a necessidade de se transformar o quadro social das favelas e áreas mais violentas a fim de promover o desenvolvimento urbano, social e econômico da população. E foi nesse sentido que o projeto procurou atuar.

Para realização do projeto foram escolhidas as comunidades do Tuiuti e da Mangueira, em virtude de questões logísticas, como a proximidade à universidade, por serem comunidades pacificadas e por estarem contempladas no Programa Federal de Aceleração do Crescimento - PAC 2, que previa obras de urbanização, melhorias de infraestrutura e intervenções de saneamento na região.

Inaugurada em novembro de 2011, a Unidade de Polícia Pacificadora da Mangueira atende a mais de 17 mil moradores, segundo dados do Governo do Estado do Rio de Janeiro $^{6}$. Telégrafos, Pindura Saia, Santo Antônio, Chalé, Faria, Buraco Quente, Curva da Cobra, Candelária e outros são pequenos núcleos populacionais que formam o complexo do Morro da Mangueira. Já a UPP Barreira/Tuiuti foi inaugurada em abril de 2013 e atende às comunidades da Barreira do Vasco e do Tuiuti, em São Cristóvão, beneficiando mais de 10 mil habitantes. Antes da inauguração, a comunidade do Tuiuti também pertencia a UPP da Mangueira.

\section{Multimídia Impacto Digital: ações e resultados}

O projeto Multimídia Impacto Digital foi coordenado pelo Centro de Tecnologia Educacional da UERJ (CTE) em parceria com o Instituto Multidisciplinar de Formação Humana com Tecnologias (IFHT) e contou com o financiamento do Ministério da Educação através do Programa de Extensão Universitária (PROEXT/2011), que tem como objetivo apoiar as instituições públicas de ensino superior no desenvolvimento de programas ou projetos de extensão.

As ações extensionistas ocorreram em duas etapas, na comunidade do Tuiuti e na Mangueira. Organizações sociais dessas comunidades também atuaram no desenvolvimento das atividades: a ONG Nova Chance e o Centro Cultural Cartola.

\section{Primeira Fase- Comunidade do Tuiuti}

A primeira fase do projeto teve início com a realização de visitas à, até então, UPP Tuiuti/Mangueira. As primeiras visitas tiveram como objetivo permitir à equipe conhecer a comunidade local e a ONG Nova Chance, parceira do projeto e local de realização das ações. Os moradores foram entrevistados, de modo a traçar um primeiro perfil e registrar suas demandas. A realização das entrevistas foi importante para estabelecer contato com a comunidade, perceber seus anseios e, principalmente, conhecer melhor o entorno social. E, a partir dos dados coletados, foi possível planejar o primeiro bloco de oficinas a ser ofertado para a comunidade. 
Nas visitas seguintes, a equipe divulgou as ações do projeto para os moradores e realizou o cadastramento de crianças e adolescentes interessados em participar das atividades.

Foram ofertadas oficinas de fotografia e vídeo, que contaram com 16 participantes de 10 a 14 anos de idade, moradores da comunidade do Tuiuti. Na oficina de fotografia, a turma trabalhou com câmera escura, aspectos da técnica e da linguagem fotográfica através de atividades práticas. Já a oficina de vídeo teve como objetivo desenvolver etapas de realização de um filme, como preparação de roteiro, decupagem, papel da fotografia, da arte, da produção, da gravação e da edição.
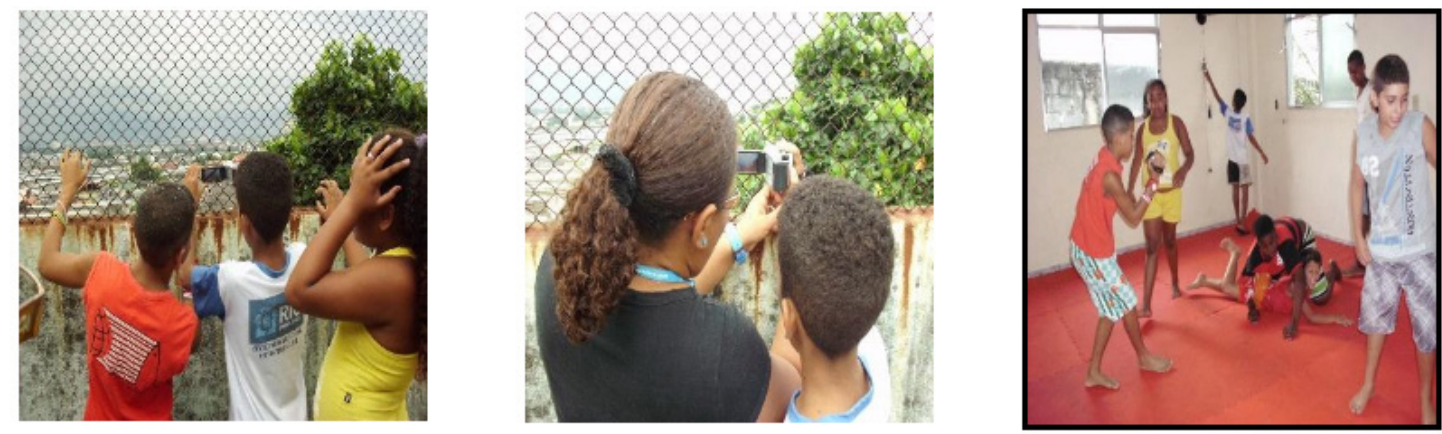

Oficina de vídeo realizada no Tuiuti.

O contato com este pequeno grupo permitiu à equipe de trabalho sentir o grau de aceitação/resistência da comunidade à UERJ, assim como o que deveria ser ajustado para as oficinas seguintes.
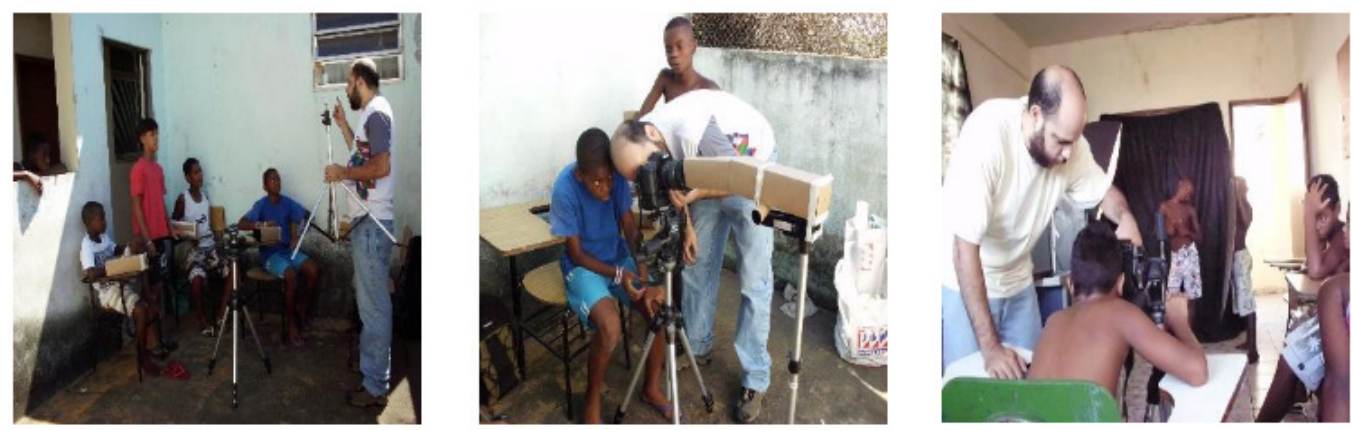

Oficina de fotografia realizada no Tuiuti.

Nas oficinas de fotografia e vídeo realizadas no Tuiuti, foi possível observar que tanto crianças quanto adolescentes, em sua maioria, fizeram sempre menção à violência através das fotos, do próprio registro e da comunidade, sempre em posição de luta. Estas fotos são a base de uma narrativa imagética, imagens que se comunicam e produzem outras imagens, são representações digitais que ainda precisam ser mais estudadas, principalmente se considerarmos a "mídia como uma produção cultural humana e histórica."7 

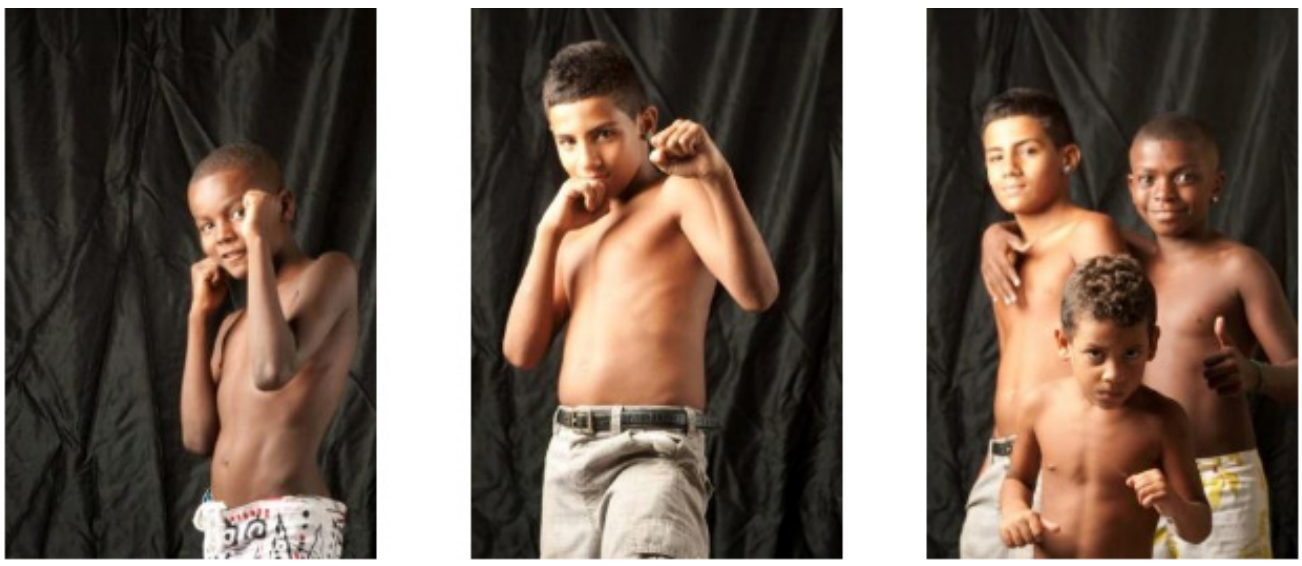

Participantes da oficina de fotografia do Tuiuti fazendo poses de luta.

Foi possível constatar que, mesmo com a UPP, a violência ainda se fazia presente na comunidade, pois foi necessário encerrar a primeira fase do projeto antes do previsto, em virtude de conflitos entre a polícia e criminosos locais. Por diversas vezes a equipe do projeto não pôde realizar as atividades planejadas, pelo fato da ONG Nova Chance se encontrar fechada a mando dos traficantes. Tal fato evidencia como a violência e a criminalidade prejudicam os moradores dessas comunidades nos mais diversos níveis, uma vez que, além de terem a sua segurança ameaçada, se veem segregados no que diz respeito às oportunidades de educação e cultura.

\section{Segunda Fase- Comunidade da Mangueira}

Na segunda etapa do projeto, foram realizadas visitas ao Morro da Mangueira para aproximação da equipe com a comunidade local e para conhecimento do Centro Cultural Cartola, outro parceiro e local de realização das oficinas. Em paralelo, foram realizadas pesquisas com os moradores, além da divulgação das ações e o registro dos moradores interessados em participar das atividades.

Após as inscrições, foi identificada uma mudança em relação ao público contemplado na primeira etapa. O público-alvo do projeto era composto de crianças e adolescentes; contudo, o grupo atingido na Mangueira foi bastante heterogêneo, contando com alto número de adultos e idosos. Neste sentido, foi necessário que o planejamento fosse refeito e os programas das oficinas adequados a este novo grupo.

O que poderia ter sido um desafio tornou-se uma grande oportunidade: a própria heterogeneidade foi um ponto forte das oficinas, pois permitiu uma maior troca de conhecimentos e experiências entre os participantes, já que cada um tinha uma história de vida e anseios diferentes. No decorrer das oficinas houve ajuda mútua, o que contribuiu para um trabalho mais colaborativo junto à equipe do projeto.

O segundo bloco de oficinas foi composto por turmas de fotografia, vídeo, cinema, design gráfico, história em quadrinhos e informática, com um total de 135 inscritos. Entre os participantes constavam não só moradores da comunidade da Mangueira, mas também de bairros próximos, como São Cristóvão. 
Ao longo das oficinas foi possível perceber a existência de diferentes níveis de interesse entre os participantes, como também de conhecimento prévio sobre os conteúdos abordados. Coube à equipe do projeto ter a percepção das dificuldades do grupo e criar mecanismos para estimular seu interesse, o que se mostrou não só um dos desafios para a realização das oficinas, como também um grande diferencial para os participantes.

As atividades foram planejadas de forma conjunta com os professores das oficinas e a equipe pedagógica do projeto, uma vez que o grupo já conhecia o perfil e a demanda dos moradores. Dessa forma, foi possível elaborar um planejamento mais apropriado, com o intuito de proporcionar aos participantes diferentes alternativas para a construção do conhecimento, através de atividades diversificadas e contextualizadas, levando-os à melhor compreensão das técnicas apresentadas por meio de um ambiente de trabalho amistoso e atrativo, onde todos tiveram a oportunidade de trabalhar a cooperação, o respeito e a convivência em grupo.

A oficina de fotografia teve como objetivo abordar técnica e linguagem fotográfica. Visitas técnicas, aulas externas e produção coletiva de conteúdo proporcionaram uma maior articulação entre teoria e prática, explorando sensibilidade e percepção do olhar fotográfico.
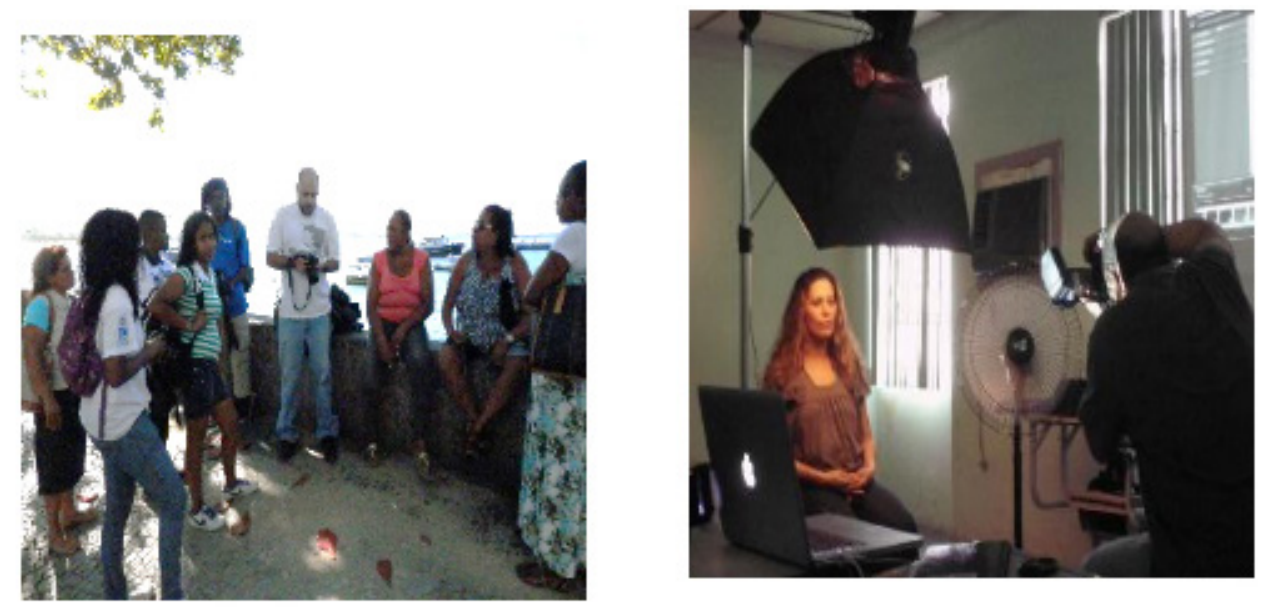

Oficina de fotografia realizada com a comunidade da Mangueira.

Na oficina de vídeo foram trabalhadas noções da elaboração de argumentos, desenvolvimento de roteiro, produção, desprodução e pós-produção, assim como as questões técnicas de leitura, decupagem e cronogramas de produção. Os participantes puderam produzir seus próprios vídeos, aplicando os conhecimentos constituídos durante as aulas. Foi realizada, ainda, uma visita ao Centro de Tecnologia Educacional da UERJ, para que pudessem conhecer o trabalho da TV UERJ, observando como funciona um estúdio de gravação e edição, bem como o cotidiano dos profissionais da área. 

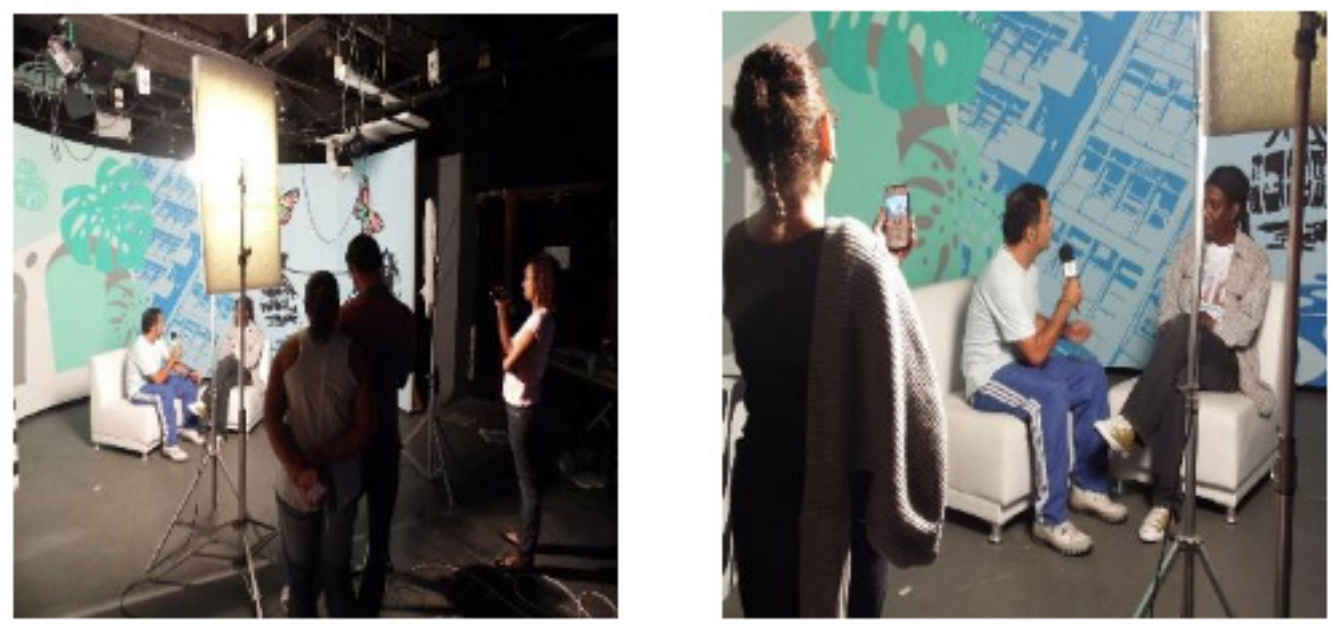

Visita da turma da oficina de vídeo ao estúdio da TV Uerj.

A oficina de cinema constituiu um espaço de reflexão, discussão e troca de conhecimentos sobre a área, lançando o olhar sobre o processo de criação dos filmes. Foram abordados aspectos históricos, técnicos e sociais da indústria e da linguagem cinematográfica, ilustrados em aula pela exibição comentada de trechos de filmes. As aulas desta oficina aconteceram no campus Maracanã da UERJ, a fim de aproximar os participantes do espaço universitário.
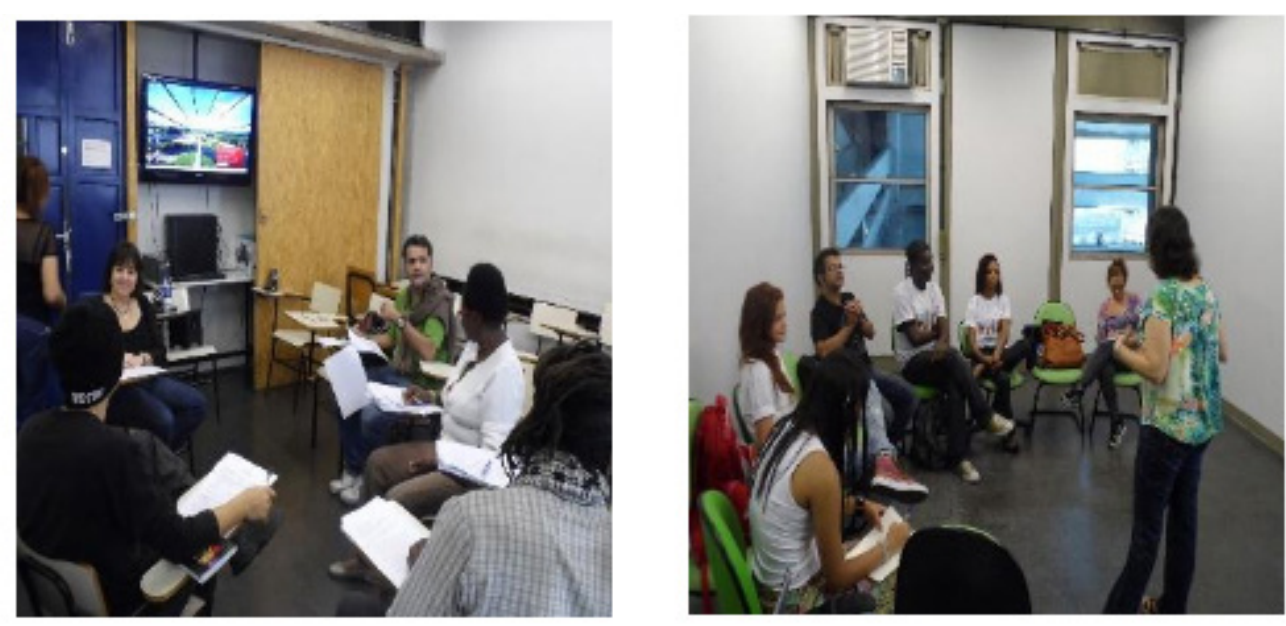

Oficina de Cinema.

A oficina de Design Gráfico contou com o grupo de participantes mais diversificado. Os alunos possuíam conhecimentos variados, sendo alguns iniciantes no assunto e outros profissionais da área de ilustração e fotografia que buscavam se atualizar e conhecer novos programas de edição. Ao longo de toda a oficina o grande desafio do professor foi encontrar um ponto de equilíbrio no conteúdo para que todos pudessem participar, que desse modo tornou possível se realizar um trabalho colaborativo. Como 
proposta final, os integrantes da oficina elaboraram uma capa de livro (fictício), onde os conteúdos abordados durante as aulas foram aplicados.
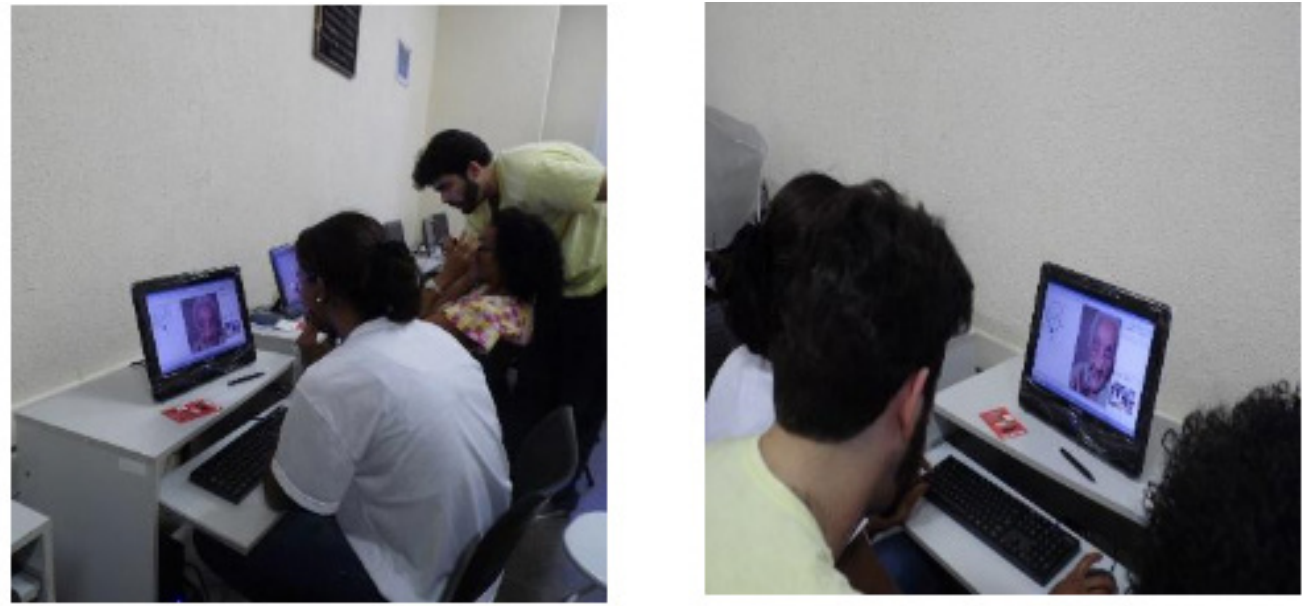

Oficina de Design Gráfico.

Na oficina de história em quadrinhos (HQ) foram praticados a construção da forma, o desenho anatômico e de personagem, além da linguagem dos quadrinhos, incluindo o desenvolvimento de roteiros. Os alunos criaram sua própria página de história em quadrinho, onde puderam aplicar todas as técnicas aprendidas nas aulas.
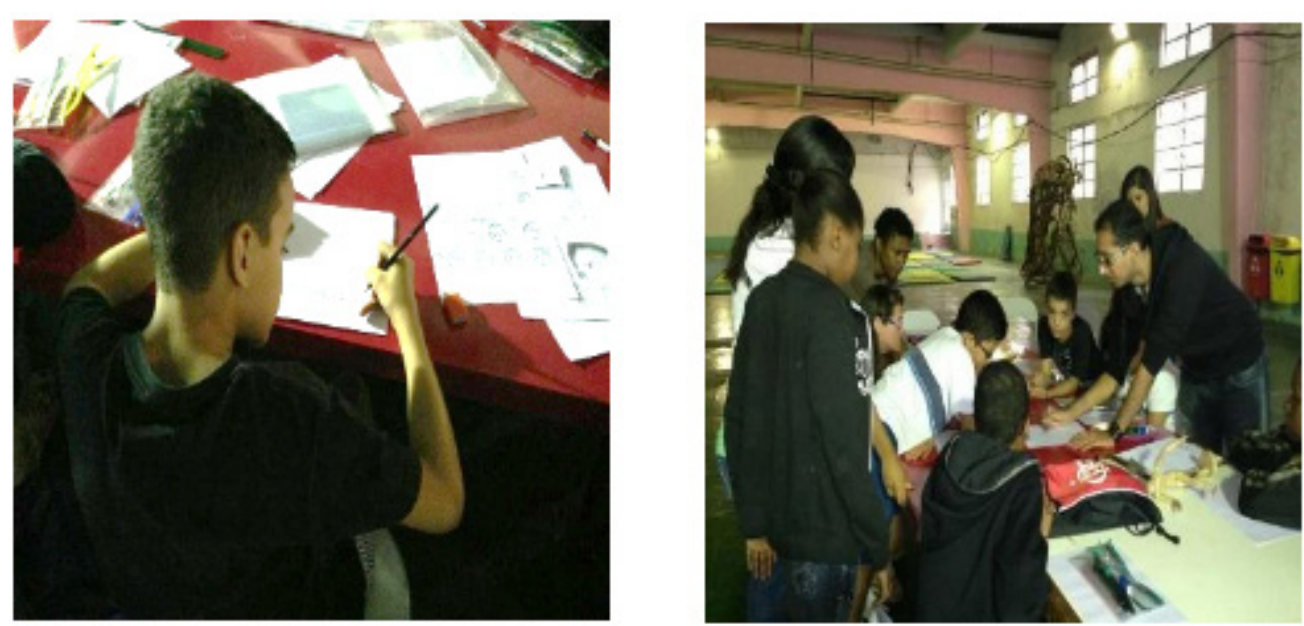

Oficina de desenho e história em quadrinhos.

A oficina de informática teve como objetivo trabalhar conceitos básicos de software e hardware, assim como recursos de editores de imagem e de texto. Nas duas turmas realizadas, houve predominância de alunos adultos, a maioria com pouco conhecimento de informática. O desafio destas oficinas foi equilibrar o conteúdo de modo a atender tanto aqueles que já possuíam algum conhecimento prévio quanto os que nunca haviam sequer ligado um computador. 

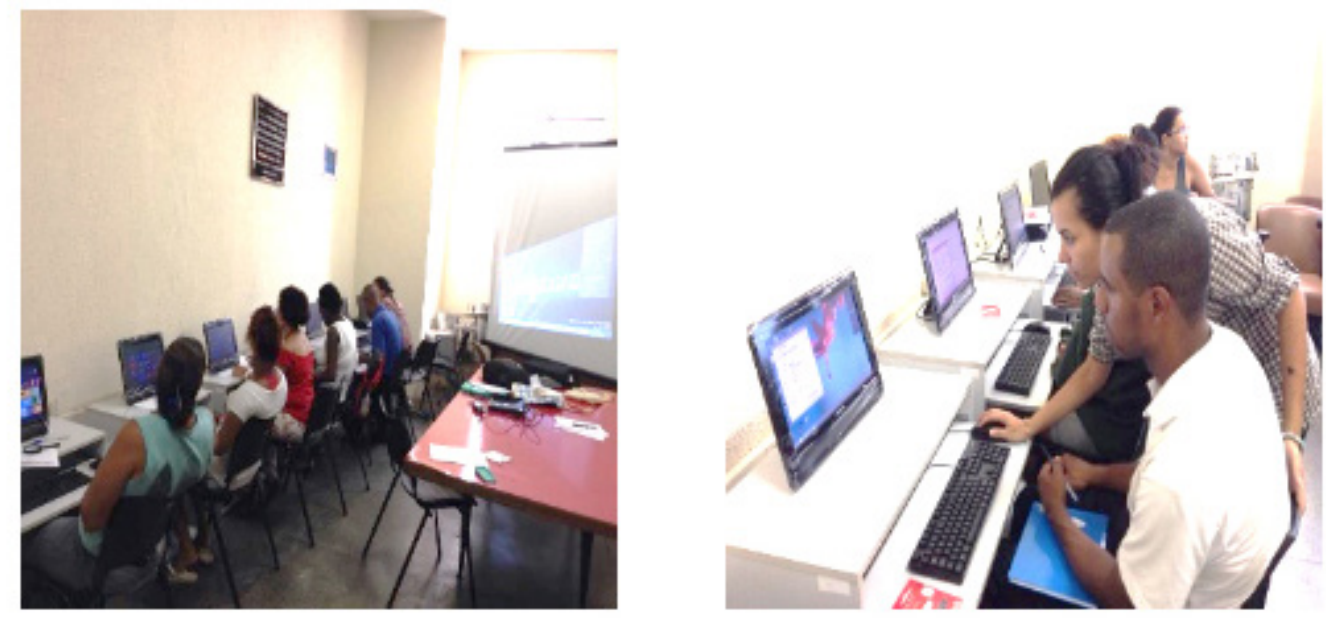

Oficina de informática.

Em síntese, durante a realização das oficinas os participantes produziram vídeos, roteiros de filmes, ensaios fotográficos, histórias em quadrinhos, textos e ilustrações, desenvolvendo habilidades que concorrem para a construção da inteligência, tais como: identificar, isolar/relacionar, combinar, comparar, selecionar, classificar, ordenar; codificar, esquematizar, produzir, transformar, criar, conceituar, memorizar, transpor e reaplicar conhecimentos.

Além disso, foi possível fomentar a discussão de temas contemporâneos a partir da reflexão de todas as etapas da construção midiática, começando pela escolha do tema, até chegar ao seu produto final. Nessa medida, a produção realizada pelos participantes, contribuiu no desenvolvimento da imaginação, da memória, da sensibilidade, entre outras capacidades.

Com a conclusão do projeto, os equipamentos adquiridos, como computadores e impressoras foram doados ao Telecentro do Centro Cultural Cartola, modernizando o espaço, em benefício dos moradores da comunidade da Mangueira. Espera-se com isso que o Telecentro se torne um polo de educação, inclusão digital, produção midiática, democratização de informação e ponto de encontro dos moradores.

\section{Resultados}

As oficinas contaram com um total de 135 inscritos. No início de cada turma foi aplicada pesquisa para identificar o perfil e interesse dos participantes. E, ao final, foi efetuada nova pesquisa para avaliação dos participantes em relação ao trabalho desenvolvido. Além das pesquisas, houve observação e registro de todas as aulas por parte de estudantes de Pedagogia, bolsistas do projeto, que desenvolveram relatórios de cada atividade.

A média de idade do público participante do projeto foi de 36 anos, evidenciando a mudança do público atendido em relação ao grupo-alvo definido inicialmente no projeto, que era composto somente por crianças e adolescentes.

A divulgação das oficinas foi feita através de cartazes e panfletos distribuídos nas co- 
munidades e escolas próximas. Contudo, entre os participantes constavam não só moradores do corpo social, mas também de bairros próximos, como São Cristóvão (26\%), Maracanã (14\%) e Tijuca (6\%), que tomaram conhecimento das oficinas através da indicação de amigos.

O grau de escolaridade da maior parcela do grupo era de ensino médio completo (31\%), em seguida com ensino fundamental completo (25\%) e por fim, os que cursavam o ensino médio (20\%).

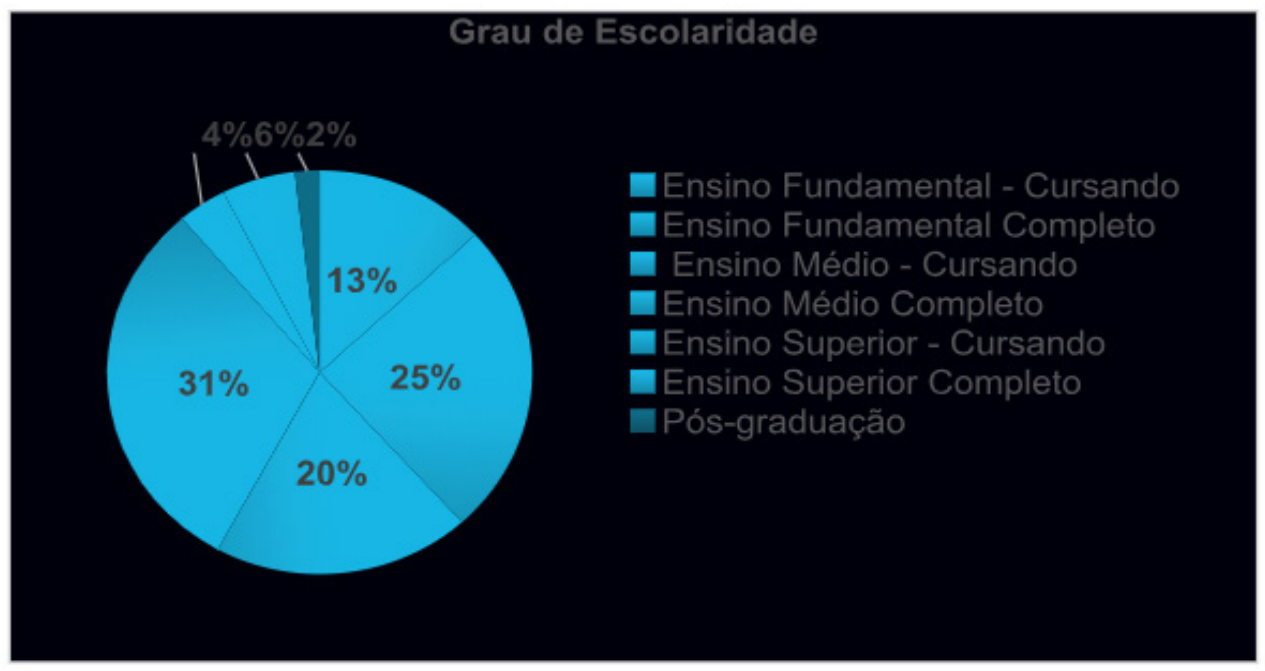

Grau de escolaridade dos participantes

Entre as razões que levaram os moradores a participar das atividades do projeto estavam o desejo de conhecer as áreas das oficinas (37\%) e o interesse profissional (29\%), como evidencia o relato de um dos inscritos na oficina de fotografia: "Meu interesse nas aulas é de conhecer a área, ter uma noção para aperfeiçoar e quem sabe fazer desta minha profissão".

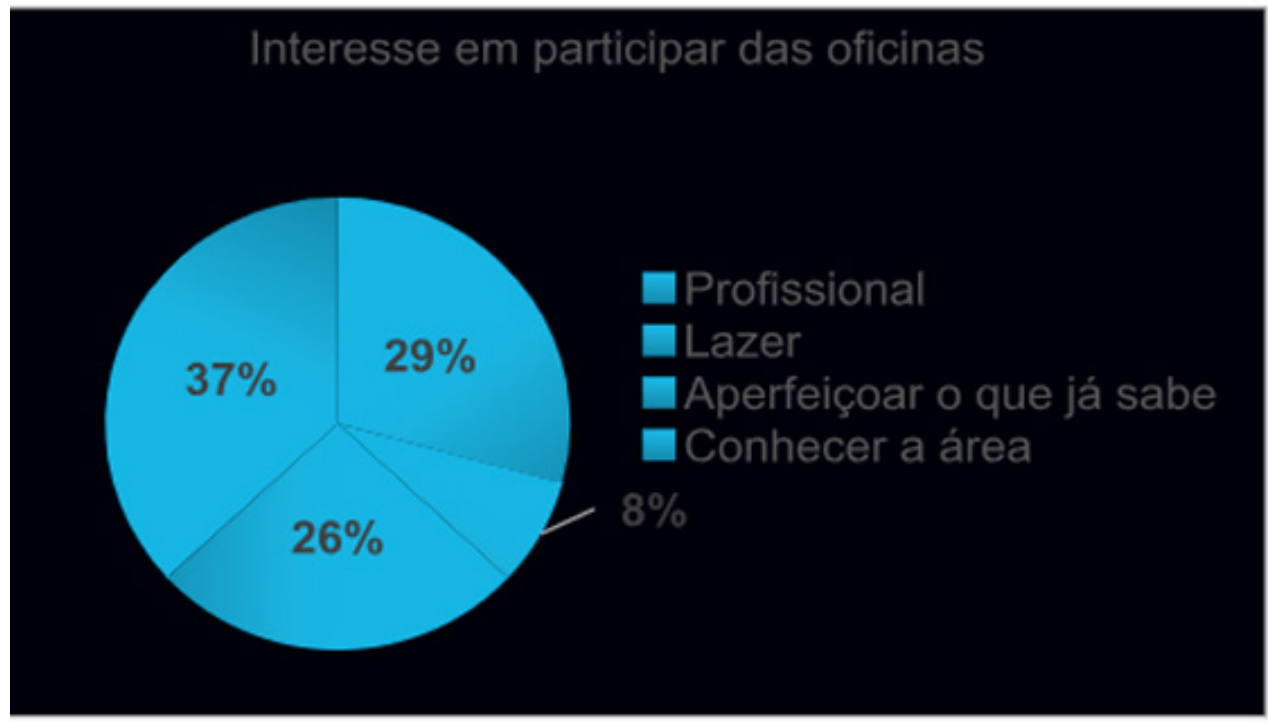

Interesse em participar das oficinas 
A grande maioria (91\%) acreditava que a participação nas oficinas poderia proporcionar algum tipo de renda extra.

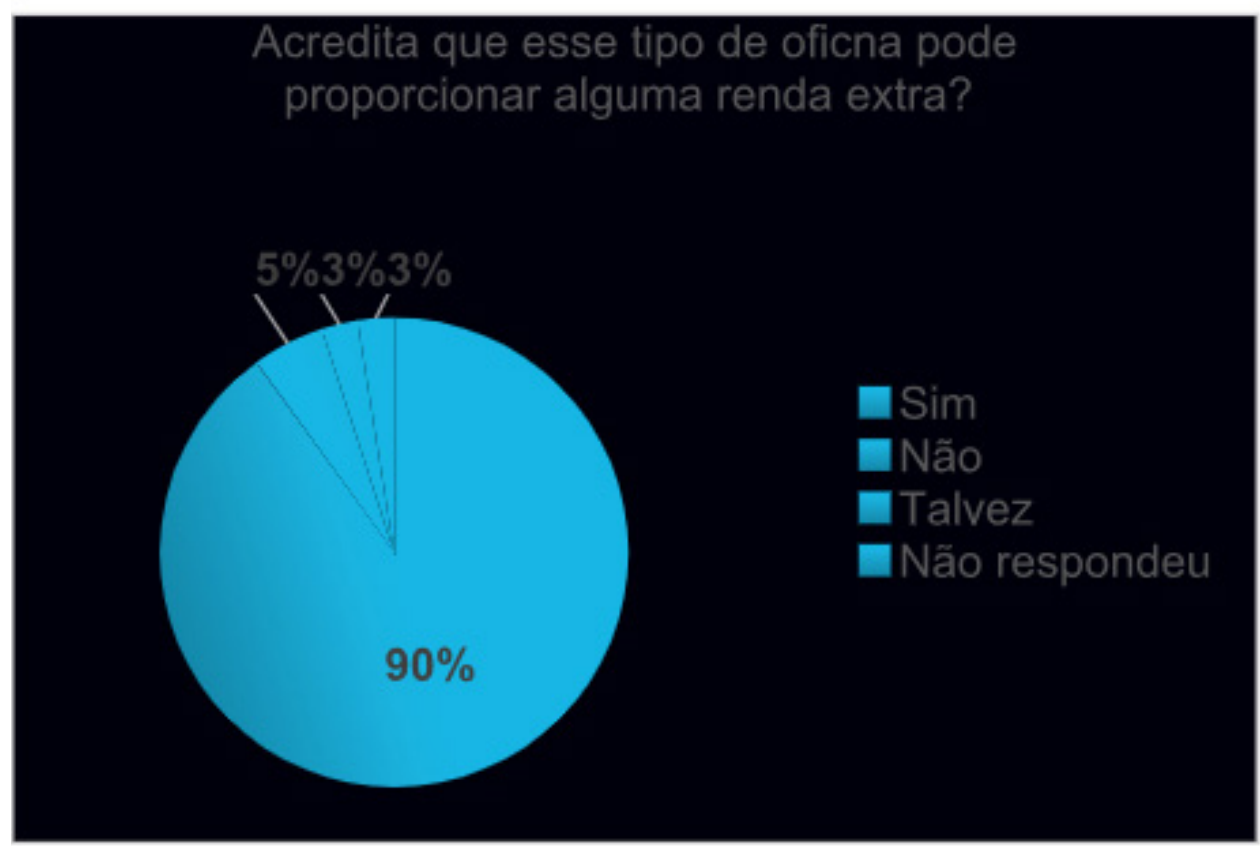

Acredita que a oficina pode proporcionar alguma renda extra.

Durante as aulas os participantes demonstraram um alto grau de interesse e satisfação em relação aos conteúdos aprendidos, o que também foi confirmado na pesquisa. Quase a totalidade do público atendido pelo projeto informou acreditar que esse tipo de atividade contribui de forma positiva para a sua formação (92\%). Também foi quase unânime a crença de que a participação nas oficinas poderia proporcionar algum tipo de renda extra (90\%).

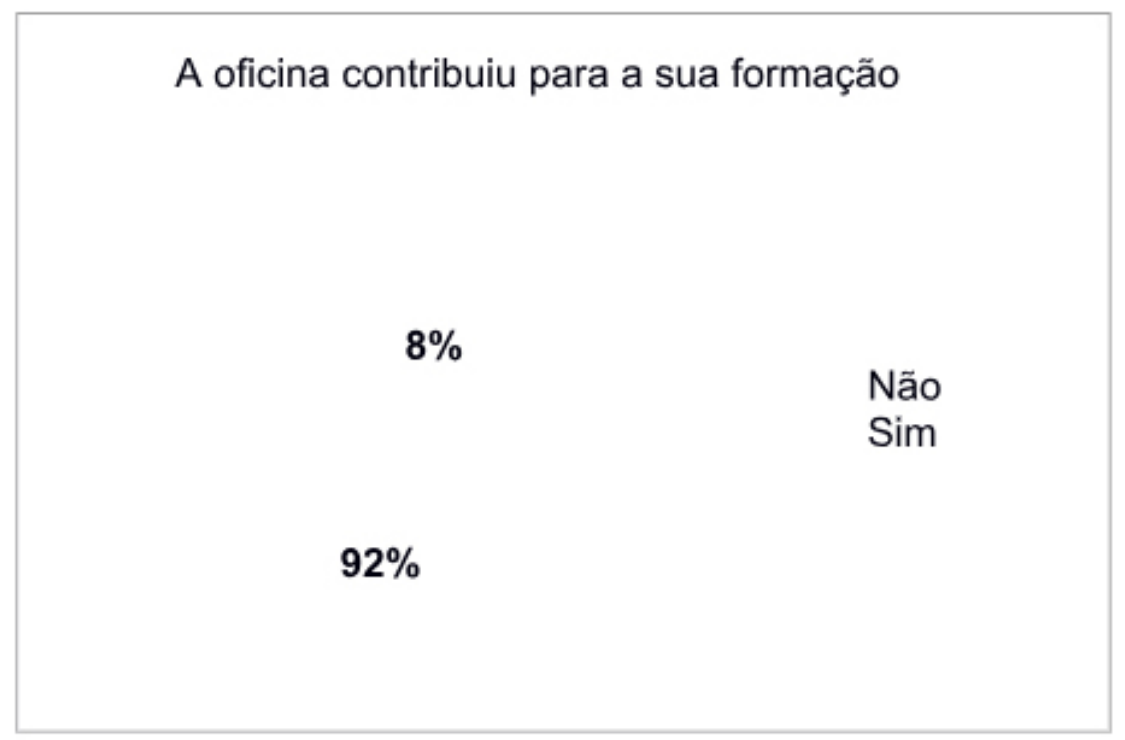

Contribuição das oficinas para a formação. 
Quanto às oficinas, a maioria classificou-as como muito boas e informou esperar um novo bloco de cursos, mostrando grande interesse em oficinas com carga horária maior. As avaliações de todas as oficinas foram positivas e o grupo relatou como contribuíram para o acesso à informação e a aquisição de novos conhecimentos, conforme relatos dos moradores:

O curso ser gratuito é um grande ponto positivo, pois não teria condições de pagar um curso desse porte. (Participante da oficina de design gráfico)

O curso é ótimo, o professor explica muito bem, a dinâmica é também muito boa. Minha sugestão é que incluam mais cursos. (Participante da oficina de fotografia)

Seria muito bom se este curso continuasse por mais tempo, vou ficar com muita saudade, achei maravilhoso, as professoras são maravilhosas e muito prestativas. (Participante da oficina de informática)

Essas respostas indicam, também, a demanda existente por uma maior oferta de oportunidades de educação e formação profissional nessas comunidades:

Sugiro organizar um cine clube para que possamos nos encontrar uma vez ao mês. (Participante da oficina de cinema)

Façam mais oficinas. (Participante da oficina de vídeo)

Incluam mais cursos no projeto. (Participante da oficina de fotografia)

Seria muito bom se este curso continuasse por mais tempo, vou ficar com muita saudade, achei maravilhoso. (Participante da oficina de informática)

Os resultados das avaliações e relatos dos participantes reforçam o quanto a universidade tem a oferecer ao público e contribuir para a sociedade através de ações extensionistas, proporcionando a reflexão e a troca de experiências entre as comunidades local e acadêmica.

\section{Considerações Finais}

O acesso às tecnologias digitais de informação e comunicação e os conhecimentos disseminados nas oficinas midiáticas auxiliaram a inclusão digital das duas comunidades participantes do projeto, contribuindo para a inclusão social, a melhoria da aprendizagem e da qualidade de vida de seus moradores.

Consideramos a importância de incluir digitalmente não apenas na forma da técnica, mas sim possibilitando que os indivíduos sejam partes atuantes de uma nova forma de agir numa sociedade digital. Neste sentido, é fundamental distinguir o acesso às TDICs do processo de construção do conhecimento. Além de aprender sobre os aspectos técnicos de utilização, o indivíduo deve se apropriar das tecnologias. O usuário deve ser mais que um receptor de conteúdo, ele também deve produzi-lo e efetivamente participar desse contexto tecnológico.

Acreditamos no fato de que a inclusão digital caminha junto à inclusão social. Quanto mais desenvolvida a sociedade, maiores condições ela terá de integrar pessoas às novas tecnologias. E quanto maior o acesso, mais se amplia a chance de integração social. É de extrema importância que todos tenham a oportunidade de se apropriar de forma significativa das tecnologias e linguagens, pois este é um dos caminhos contra a desigualdade. 
Destacamos a importância de termos dado os primeiros passos em direção a inserção das mídias digitais no cotidiano das comunidades do Tuiuti e da Mangueira, não apenas do ponto de vista técnico, mas sim de uma outra forma de agir na contemporaneidade.

\section{Referências}

1. KENSKI, Vani Moreira. Educação e tecnologias: O novo ritmo da informação. Campinas, SP: Papirus, 2007.

2. POSTMAN, Neil. O fim da educação. Redefinindo o valor da escola. Rio de Janeiro: Graphia, 2002. (p. 185).

3, PRETTO, Nelson De Luca. Sociedade da Informação mas... que sociedade?!.2001. Disponível em: http://www2.ufba.br/ pretto/textos/socinfo\%20sbpc/socinfo\%20 em\%20debate.htm. Acesso em: 18 de janeiro de 2016.

4. CASTELLS, Manuel. A Sociedade em Rede. vol.1 Trad. Roneide Venancio Majer com a colaboração de Klauss Brandini Gerhardt. 8 ed. São Paulo: Paz e Terra, 2005.

5. BELLONI, Maria Luiza. O que é Mídia-Educação. 2.ed. Campinas, SP: Autores Associados, 2005. .

6. Governo do Estado do Rio de Janeiro. Unidades de Polícia Pacificadora - Informações. Disponível em: http://www.upprj.com/index.php/informacao/informacao-selecionado/upp-mangueira/Mangueira. Acesso em: 15 de dezembro de 2015.

7. SMOLKA, Ana Luiza. Entrevista realizada durante o $\mathbf{2}^{\circ}$ Encontro Internacional Rio Mídia. Disponível em: http://portalmultirio.rio.rj.gov.br/portal/riomidia/rm_entrevista_ conteudo.asp?idioma=1\&idMenu=4\&label=Entrevistas\&v_nome_area=Entrevistas\&v_ id_conteudo=66591. Acesso em: 09 de dezembro de 2015. 